ASSESSING THE CREATIVE CAPACITY OF PLANNERS WITHIN THE GTA

by

Alexander Hans Maximilian Lader, BA hons., York University, 2009

\author{
A Major Research Paper \\ presented to Ryerson University
}

in partial fulfillment of the requirements for the degree of

Master of Planning

in

Urban Development

Toronto, Ontario, Canada, 2011

PROPERTY of

RYERSON UNIVEFSTYY LERAAY

C Alexander Lader 2011 


\section{Author's Declaration}

I hereby declare that I am the sole author of this major research paper.

I authorize Ryerson University to lend this paper to other institutions or individuals for the purpose of scholarly research.

Signature

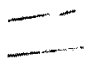

I further authorize Ryerson University to reproduce this paper by photocopying or by other means, in total or in part, at the request of other institutions or individuals for the purpose of scholarly research.

$\overline{\text { Sigr }}$ 


\title{
ASSESSING THE CREATIVE CAPACITY OF PLANNERS WITHIN THE GTA
}

\author{
(C) Alexander Lader, 2011 \\ Master of Planning \\ in \\ Urban Development \\ Ryerson University
}

\begin{abstract}
Given the assertion that planners exist within a restrictive environment that inhibits their ability to maximize creativity within their profession, this paper investigates what these restrictions are, and how municipal planners deal with them to maximize creativity. To do this, the opinions and experiences of ten currently practicing planners from municipalities within the Greater Toronto Area (GTA) are presented. Findings suggest that barriers to creativity can be attributed to four main categories: provincial legislation; corporate standards and regulations; internal culture/leadership; and resource limitations. They also indicate that individual creativity often occurs on a small scale, in a manner that allows for the gradual and incremental overcoming of restrictions.
\end{abstract}

Key words: Planning, Creativity, GTA 


\section{Acknowledgements}

First and foremost, I offer my sincerest gratitude to my supervisor, Dr Sandeep Agrawal, whose genuine interest, patience and valuable suggestions have encouraged me to complete this seemingly daunting study.

I would also like to offer gratitude to Professor Lawrence Altrows for providing valuable feedback on my draft copy.

Lastly, this paper would not have been possible without the generosity, thoughtfulness, and cooperation of the ten municipal planners that agreed to participate in this study. For that, I offer my deepest gratitude. 


\section{$\underline{\text { Dedication }}$}

To my family, friends, and colleagues, whose tolerance of messy rooms, evasive behaviour, and genuine support during the creation of this paper is greatly appreciated. 


\section{Table of Contents}

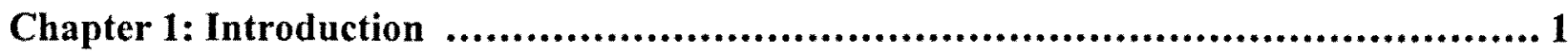

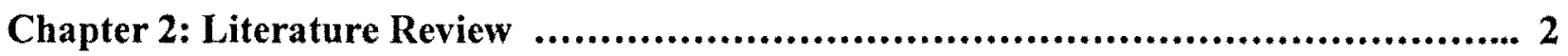

2.1 What is Creativity ........................................................... 2

2.2 Why Assess the Creative Capacity of Planners? ............................... 7

2.3 Conditions Required for Creativity in Planning ............................. 11

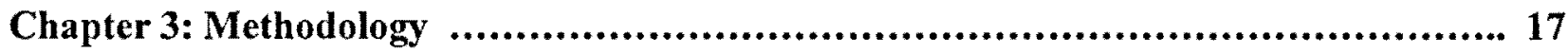

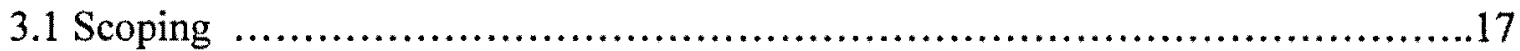

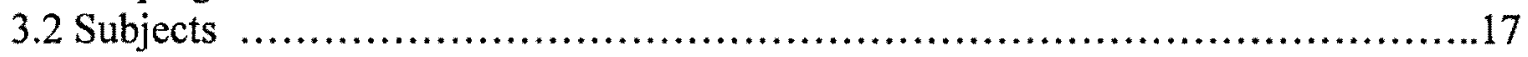

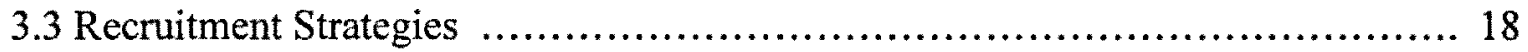

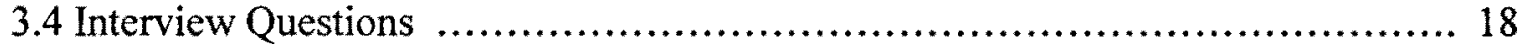

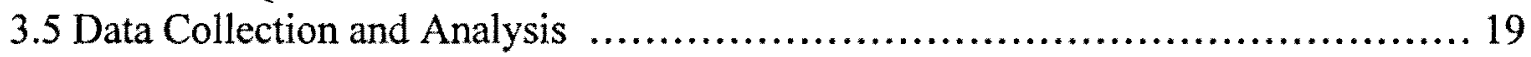

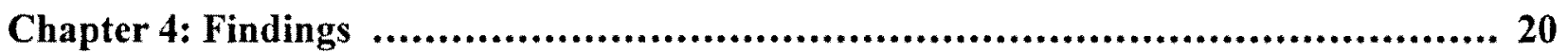

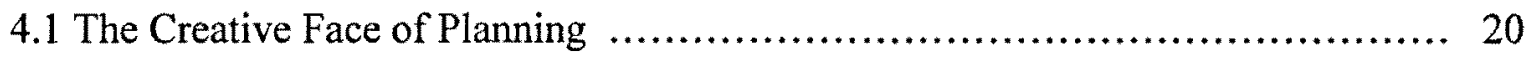

4.1 .1 Definitions ......................................................... 20

4.1.2 Opportunities for Creativity ....................................... 23

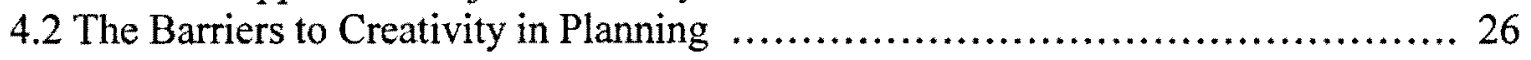

4.2.1 Provincial Legislation ............................................. 27

4.2.2 Corporate Standards and Regulations .................................. 29

4.2 .3 Governance Structure and Leadership .............................. 32

4.2.4 Resource Limitations ................................................... 36

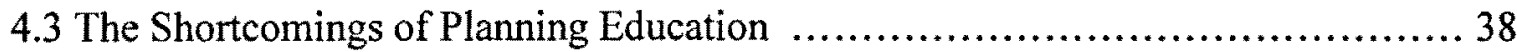

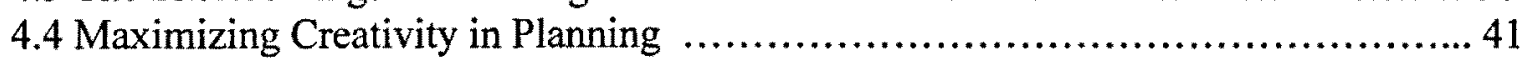

4.4.1 Leadership ......................................................... 41

4.4.2 Individual Behaviour ...............................................44

Chapter 5: Discussion and Conclusions

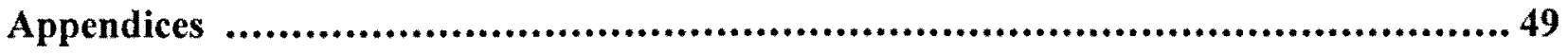

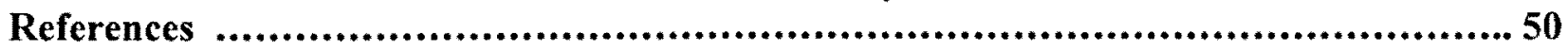




\section{List of Figures}

1. Municipalities Within the Greater Toronto Area .17 


\section{List of Appendices}

Appendix A: List of Interview Questions 49 


\section{Chapter 1: Introduction}

Creativity lies at the very core of the planning profession. It is what ensures progression and adaptation to an ever evolving political, social and physical landscape, allowing planners to stay at the forefront of change; to play a proactive role in the city/place-making process, rather than a reactive one that only responds in an ad-hoc manner to the world around them. Creativity is like the artificial Hare in a dog race: eternally steps ahead of the racing beast nipping at its heels, safe until it slips off its track.

In planning school, creativity serves as the foundation of the curriculum. Students are pushed to think in a multi-dimensional manner, mindful of the surrounding economic, social, and environmental milieu; forced to assume the perspective of landowner, resident, conservation officer, and social worker all at once. Students are assigned papers and projects that require the re-thinking of existing regulations and urban conditions, previous developments and theories, all with Daniel Burnham's mantra "make no little plans" lingering in the backs of their minds. Despite this culture of creativity that exists within the academic setting, planners in the "real world" function within a restrictive framework that inhibits their ability to carry out creative ideas. Generally speaking, strict government regulations and legal framework; corporate pressure and influence; NIMBY attitudes of local communities; and political agendas (to name a few) are real factors that hamper planning innovation and progression (Kunzmann, 2005). Given these assertions, how do currently practicing planners deal with these restrictions? Do these assertions hold true, and if so, how are planners maximizing their creative potential? To answer these questions, this paper will present the opinions and experiences of ten currently practicing planners from within the Greater Toronto Area (GTA), with the intent to provide insight into the relationship between real-world planners, and creativity. 


\section{Chapter 2: Literature Review}

\subsection{What Is Creativity?}

Before we can assess the capacity of planners to maximize creativity within their positions, we must clarify what we mean by "creativity", and how it is understood in the context of planning. Within the academic literature, there exist many different definitions of the concept. At its most basic definition, "creativity" is the ability to bring into being something that was not there before; to create - create-ivity (De Bono, 1992 from Kunzmann, 2005). While this definition captures the essence of the concept, further literature reveals its inherent complexity. For Pink (2005), creativity is not just the creation of something new. Rather, it is directly related to intellectual capacity. It requires a shift from left-brain linear, logical, computer-like thinking, to right-brain thinking ruled by empathy, artistry and emotion. This understanding stems from Edward de Bono's concept of "Lateral Thinking"; a way of thinking that seeks the solution to problems using unorthodox methods, which would normally be ignored by logical thinking. De Bono strengthens this concept by differentiating it from vertical thinking, which is associated with rigid, linear thought through the path of least resistance, as opposed to exploring different paths for solving a task - thinking about thinking (De Bono, 1968). Similarly, Jary and Jary (2000) note creativity requires divergent thought; that is, thoughts toward solutions in several directions, enabling the generation of as many plausible responses as possible. In addition, Albrechts (2005) makes the assertion that creativity is not only an individual intellectual process, but also a "social process that stimulates the ability to view problems, situations and challenges in new and different ways to invent and develop original, imaginative futures as a reaction to these problems, situations and challenges"(pg.14). 
Underlying the above definitions is the recognition that creativity is a cognitive process. Central to this understanding are two theoretical models. The first, and perhaps one of the earliest theories of creativity as a cognitive process is the five-stage model by Wallas (1926). In the first stage, one uses preparation to begin working on the problem. The second stage is incubation, in which one can begin to work on other things, while their mind constantly thinks about the problem consciously or subconsciously. The third stage, which is sometimes dropped from the model, is intimation, where one begins to realize that they are about to have a breakthrough. This leads directly to the illumination stage, where a plausible solution emerges in one's mind. Finally, the verification phase tests these ideas and develops them further to ensure a solution has been found (Wallas, 1926 cited in Kaufman, 2009). The second influential model of creativity as a cognitive process is Guilford's model of divergent thinking (1967). For him, divergent thinking was an inherent part of creativity, and could be boiled down into four components:

Fluency - quite simply, fluency refers to the ability to generate a number of different ideas in response to a question.

Flexibility - the ability to generate different types of ideas. For example, if asked what the different functions of a garage could be, answers relating to automotive storage would be one type of idea, and answers relating to conversion for additional dwelling space would be another type.

Originality - The ability to produce unique or unusual ideas.

Elaboration - The ability to develop, or explain ideas at greater detail; to further conceptualize (Guilford, 1967 from Kaufman, 2009). 
While the above definitions illustrate the understanding of creativity as a differential thinking process, the end product that these processes bring about are of equal importance. This understanding is evident in the definition given by Higgins and Morgan (2000). For them, creativity is the ability to repackage or combine knowledge in a new way, which is of some practical use or adds value. Take, for example, a response of "ship them to Uranus" when asking what an appropriate punishment for murderers would be. While this response is undeniably different and unorthodox, it is of neither practical use, nor adds value, due to its impossibility. Thus, for Kaufman (2009), creativity is more than being different; it must also be appropriate and relevant to the task at hand.

In the context of planning, it is this "repackaging" of existing knowledge for added value that is essential for progression. Kunzmann (2005) makes this clear in his understanding of the concept: "(creativity) is the capability to manage projects, procedures or approaches beyond dayto-day routine and to make well-balanced decisions, even if these are based on incomplete information (pg.7). In a profession governed by legal regulations, financial rules and political and community sensitivities, the ability to work within (and around) these conditions certainly requires "creativity". This understanding of the concept is perhaps the most important one; creativity cannot be one thing. It is not only a new idea, product, or service, but also an adaptation, or improvement of existing ones. It is not only an end product, but also a process individual and group (Woodman et al, 1993).

In an attempt to ground these potentially abstract definitions, here are several useful examples of creativity within the context of planning. One such example is the case of Hasselt, Belgium in the late 1990 s to early 2000 s. With automobile-related externalities a growing concern in the community such as growing traffic congestion, accidents, and environmental 
contamination, the city mayor was faced with a crucial decision: building a third ring road around the city to mitigate traffic, or rethink the city's approach to transportation planning. During a period of extensive road repairs, the city offered a free shuttle bus to ease congestion and improve manoeuvrability for citizens. With this shuttle bus a large success, Hasselt's mayor made the decision to permanently implement free public transportation across the city. As a result, public transit use increased dramatically, reducing congestion, and eliminating the need for a third ring road - saving enormous expenditures. Although the overwhelming success of the temporary free transit was somewhat unexpected, this example illustrates how the visionary qualities of the city Mayor (the presence of mind to entertain solutions from different perspectives, and the leadership ability to implement an unorthodox idea) ultimately resulted in a highly beneficial, creative solution (Albrechts, 2005).

Another example of creativity is the case of Curitiba, Brazil, who's visionary Mayor led the city's shift toward a sustainable model of development through several alternative "out-ofthe-box" projects throughout the " 80 s and " 90 s. In order to avoid exponential growth in cardependency, traffic congestion and air pollution due to a rapidly growing population, city officials invested in a citywide Bus Rapid Transit (BRT) system. In combination with a new master plan, the BRT system, implemented along the city's main corridors, helped encourage future development in a linear form, rather than in a sprawling, radial manner. The BRT's efficiency (exclusive laneways allowing for unimpeded service, and short loading/unloading times due to a pre-pay fare system, extra-wide doors and raised platforms) would eventually make it the primary means of transportation within the city. Based on 1991 survey results, the BRT had led to a $28 \%$ reduction in car use, equating to a savings of approximately 27 million litres of fuel annually. As well, the system's low capital costs compared to similar mass transit 
alternatives (such as subways) made the project economically viable (Goodman et al, 2007). In addition to the successful BRT system, Curitiba's approach to river flood control marked a creative alternative to the dominant trends employed in most other Brazilian cities. Instead of creating concrete viaducts to "channelize" the Parana River to prevent flooding, city officials opted to build several small dams along its stretch, forming tiny lakes. These lakes would serve as the centre of municipal parks, straddled by protected conservation areas on the adjacent riverbanks. Not only was this project an ecological alternative for flood control, the creation of the conservation areas increased the city's green area per inhabitant from two square feet to 150 square feet (Mckibben, 2005). A third example of creativity in Curitiba was its dualistic approach to environmental conservation and the health of its squatter population. To ensure proper nutrition for its poor inhabitants, a government program was established which enabled residents in nearby favelas (squatter settlements) to exchange garbage and recyclable materials for fresh fruits and vegetables; a program serving the goals of both ecological and social sustainability (Hitchcock, 2004). Throughout these examples, creativity can be seen on different scales and forms. On a broad scale, creativity is exemplified by the city's paradigmatic shift to a sustainable model of development; a change in direction from the city's master plan developed in the 1940s (Goodman et al, 2007). On the individual project scale, creativity can be seen in the ability of city leaders and officials to consider alternative solutions to common urban issues, and take political risks.

A more recent Canadian example of creativity in planning can be seen in the design of the North Oakville Secondary Plan for Oakville, Ontario. As a departure from the traditional sprawling suburban development seen in other parts of the town, the secondary plan aims to create a "complete" urban community that reflects the local distinctiveness of Oakville's small- 
town, rural heritage and natural landscape, while combining nodes of modern pedestrian-oriented development and "prestige" employment areas (Town of Oakville, 2008). The community will ultimately be a mixture of walkable, mixed-use urban core areas, among a network of open space and protected landscape. While this development is creative for the Town of Oakville, as it . marks a paradigm shift towards sustainable community development, the process by which the secondary plan was conceived provides further examples of creativity in planning. For instance, members of the consulting team emphasized the importance of a "dynamic participation" approach that facilitated multi-way communication with stakeholders, rather than a "presentation" approach. This "dynamic" approach to communication involved the creation of an outreach program, containing several different methods of engagement. This included the creation of a study website, showing plan updates/drafts and allowing the public to post feedback; the creation of several working sessions for stakeholders and staff to inform and encourage discussion/answer questions; focus groups (6 targeting adults, and one targeting youth) to connect with members of the general public unable to participate in the formal consultation process; and the regular participation of senior consulting team members in cable television programs to provide information and answer questions (Town of Oakville, 2003). This example illustrates that creativity in planning can occur both in the concept of a project, and the process by which the final product is reached. In this case, the efforts of the consultation team to employ numerous and unique methods of community outreach are indicative of a creative planning process.

\subsection{Why Assess the Creative Capacity of Planners?}

As alluded to in the introduction, creativity is an essential requirement for progression and adaptation, especially in the ever-evolving profession of city planning. The importance of 
creativity in planning is evident in the curricula of today's planning schools; professors push students to strive for "out of the box" solutions during studio projects and essays. However, despite this culture of creativity that exists within the academic setting, how well do these learned ideals transfer into the real world? Does this same creative culture exist within city offices as it does in lecture halls? While my optimistic young mind wants me to believe this is the case, existing academic literature on the topic has quelled my initial confidence. Literature suggests that planners function in a restrictive framework that inhibits their ability to be creative. As mentioned above, Kunzmann (2005) contends generally that legal regulations, financial budgets, and the political and social environment serve, in some capacity, as barriers to creativity. He also carries the sentiment that creativity in urban development seems to occur where urban planning is absent; where squatters and micro-developers are free from the confines of strict legislation to plan as they wish. In a profession that requires the voice of multiple actors, stakeholders and leaders, all too often the "why we shouldn't" community outweighs the "howto-do", or "let's try" (pg.10).

For Landry (2000), the city planning system is wrought with flaws - some individual, some systemic - that subsequently act as barriers to building a creative environment. To name but a few of these obstacles from his extensive list:

An utter lack of effort and thoughtlessness - predictability and placelessness plague so many contemporary urban landscapes. Formulaic shopping centres, subdivisions and streetscapes contribute to a homogeneous urban realm; generic models of success that are adopted from around the world eclipse local nuances and characteristics (pg. 42).

Formulaic thinking in city marketing - City marketing can be used as a tool for generating an individual identity. However, all too often, common generic themes emerge (based on natural : 
beauty, high-tech industry for example), creating a world landscape of pseudo-identical city twins. Landry uses the examples of European cities such as Berlin, Warsaw, Helsinki, Prague, Budapest, etc., who pride themselves as "gateways". He contends that reference to local characteristics is essential, however seldom made (pg. 43).

Memory erasure - Acknowledgement of natural and built heritage, social and political history is often ignored. For example, Landry references the near erasure of every historic quarter in the redevelopment of Kuala Lumpur and Singapore, and the defiant push to eliminate all remnants of the Berlin Wall. He argues that an understanding and acknowledgement of local history is a resource for creativity, triggering ideas and making connections (pg. 44).

Bureaucratic Proceduralism - creative capacity is a function of complex regulatory structures, including by-laws, licenses, special permissions and traffic restrictions, to name a few. These regulations often make change and adaptation a slow and arduous process, limiting the ability to make full use of creative talent within municipal organizations. However, one could argue these restrictions force city authorities to be creative in order to manoeuvre within these frameworks (pg. 46):

Short-termism and glamour - politicians often employ short-term logic to maximize results during their tenure, and likelihood for re-election. Although grandiose visioning can motivate and generate momentum, smaller initiatives with high-impact such as partnerships or training programmes can be overlooked (Pg. 46).

Accountability - ultimately, municipal leaders in decision-making positions must be accountable to the public. This accountability may limit risk-taking required for maximizing creativity. Reactive vs. proactive - cities often function in a reactive framework that addresses issues that have already developed. For Landry, this culture forces cities to focus on "yesterday's problem 
not tomorrow's opportunity". In order to keep up with environmental, social and economic change, a proactive culture is required to forecast and stay ahead of the curve (pg. 46). Power and patronage - long-tenured city officials often have well-established networks and professional relationships. These (closed) networks can serve to exclude communication and contribution from new personnel and departments, limiting the possibilities of creativity from "unexpected" avenues (pg. 47)

Lack of integration - for Landry, land use issues still serves as the centre of the planning profession. Despite a progression towards a more interdisciplinary outlook, there remains an insufficient level of integration with social, economic, environmental and cultural affairs (pg. 47). While it is important to recognize these deficiencies and barriers are broad generalizations, they serve as points of departure, promoting local inquisition and awareness.

To build off of Landry's extensive list of urban deficiencies, Healey (2004) explores the relationship between creativity and forms and practices of urban governance - that is, the values, norms, discourses, specific arrangements and modes of operation of a government (pg. 13). While Healey acknowledges that over-management and regulation, such as the "audit culture" that exists on urban regeneration experiments in the UK can destroy enthusiasm, interest and trust, she also notes that governance processes do have the capacity to foster (rather than hinder) creativity (pg. 14).

Perhaps the greatest barrier to progression and creativity within planning is a function of its inherent complexity in terms of the multitude of actors and stakeholders involved. For Forester (1982), the planning process is laden with unequal power relations that make true collaboration, an integral factor for maximizing creative potential, difficult to achieve. For . instance, land-use planners can be overwhelmed by powerful developers who have exorbitant 
resources (time, money, expertise and information) (pg.27), numerous groups of neighbourhood residents with differing points of view, and political agendas, all at the same time. Progression in planning is often a function of the planner's ability to mediate and negotiate between these conflicting views (pg.82)

\subsection{Conditions Required for Creativity in Planning}

The above discussion has established the importance of creativity in planning, as well as argued that planning practice is riddled with obstacles that stifle creative capacity. But what can be done to overcome these barriers; what conditions, or behaviours are required to maximize creativity; and how has planning practice evolved to address these issues? The following section will attempt to address these questions through existing literature, and serve as a link to the methodology and purpose of my research.

As alluded to before, creativity can be harnessed in many different ways; it is not only an individual process, but an organizational/group process as well. In Woodman and Schoenfeldt's interactionist model of creative behaviour, individual creativity is a complex product of contextual and social influences, as well as personality and intellectual capacity. In the group/ organizational setting, creative output is highest in conditions of democratic and collaborative leadership, organic/informal rather than mechanistic and rigid group structure, and a group composition of individuals from a variety of fields/backgrounds (Woodman et al, 1993). This contention is similar for Kunzmann (2005), who would agree that innovation and creativity can thrive in group settings composed of complex networks of informal relationships. These networks, or "creative milieus", contribute to a sense of belonging, enhancing creative capacity through a synergetic and collective learning process (pg. 5). In addition to a strong network, creativity in the restrictive framework of the planning world requires certain individual qualities. 
As Kunzmann (2005) so eloquently states: "A creative planner has to be an urban or regional guerrilla in order to undermine established bureaucratic and political agendas" (pg. 6). He goes on to emphasize that creativity in planning requires risk-taking and leadership personalities not only by planners themselves, but by all players in the planning process, including developers, researchers, educators, journalists, youth, immigrants, and even finance officers (pg. 10,11). Healey (2004) also recognizes that attitudes that encourage imagination and open-mindedness on a broad organizational level are essential for creativity (pg. 13).

The recognition of the above conditions and behaviours required for creativity (including in large part collaboration from different actors) in the academic literature is indicative of a paradigm shift in planning theory - from planning as a "systematic" practice to a "communicative action" approach (Innes, 1995). In the systematic approach of the 1940s, through the 1970s (arguably), planning was a rational profession where decisions were informed by tacit assumptions and instrumental rationality at an arms length from the nuances of local politics and socio-cultural conditions; planning was a top-down endeavour imposed by professional expertise and knowledge. An example of this is the slum clearance urban renewal schemes of the 1940s and 1950s in the Regent Park, and Cabrini-Green neighbourhoods of Toronto and Chicago respectively. For Innes, the systematic approach was deficient due to its reliance on broad-based, technological models to grow and guide healthy urban environments (pg. 184). In contrast, the communicative action paradigm, emergent in the 1980 s, functions on a less abstract level and is centred on the idea that planning is fundamentally an interactive, communicative activity. Planners under this paradigm rely on qualitative inquiry rather than deductive logic, and strive to understand the micro-scale, taking into account underlying contexts and uniqueness (pg. 185). The implicit push of this approach to understand different 
perspectives, and ground decisions based on a collaborative, holistic process, makes it inherently partial to maximizing the creative capacity of planners.

The creation of the "New Structure Plan for Flanders, Belgium" (essentially a land use plan for the region) is exemplary of the capacity of planners acting under the framework of the communicative action approach to initiate change and maximize solutions. Instead of a technocratic, top-down approach to the creation of a new structure plan that focussed on the end product, the planners in charge shifted importance on the process. Through this process, the planners aimed to establish a new planning culture, through the introduction of new planning concepts, and the integration of collaboration with key actors throughout the process. (Albrechts, 1999). Central to the achievement of these goals was the recognition of planners' highly political role as negotiator, mediator and initiator of communication between different stakeholders. From the outset, planners took control of the situation, facilitating an open dialogue with the broader planning community, private consultants and the press, in order to "make friends", in order to assert themselves on an equal basis as the other players (pg. 569). In addition, in order to garner political support for their ideas, the planners involved began a lobbying process, informing, explaining and convincing political cabinet members, different political parties and trade unions - this involved an open bargaining process, whereby strategies were developed through talks and discussions, rather than technical analyses (pg.599). In addition, and perhaps the most important method to initiating positive change, was the planners' efforts to inform, listen to, and educate members of the broader public. This proved to be the most difficult part of the process, given the lack of collaborative/communicative culture that existed within the region. Eventually, the open approach, and genuine willingness of planners to listen to community issues resulted in the sharing of important new ideas, views and critiques of the plan and process (pg. 600). Perhaps a 
key initiative to engaging with the public was the education, information and social initiatives. In an attempt to integrate key aspects of the plan (including related issues, and information) into the secondary school curriculum, Geography teachers in Flanders were given refresher courses on the plan, and equipped with all the materials needed to educate students. As well, the dissemination of brochures and pamphlets to the public were an attempt to maximize inclusion. Ultimately, the highly inclusionary and collaborative approach taken by Flanders planners resulted in the adoption of a new structure plan in 1997. For Albrechts (1999), this case illustrates that the cooperative efforts of different groups, and the facilitative leadership qualities of planners can contribute to creative and innovative end results.

One could argue that, in addition to the paradigm shift, planning practice has evolved to utilize specific techniques that attempt to maximize creative solutions. Underlying many of these techniques is the basic understanding that collaboration from a mix of people and increasing participation is important to fostering creativity (Landry, 2000). Essentially, these techniques administer different methods of community engagement, in order to maximize the number of ideas. For example, Albrechts (2005) explains that scenario building is a useful tool for conceiving different possible futures, and the process needed to achieve future goals. It serves as a visioning process that enables the recognition of multiple directions, allowing for collaboration, as well as preparation for uncontrollable future situations - a rehearsal of the future (pg.18).

In addition to scenario building, future search, a technique originating from both the business and community development disciplines (future search network, 2003), aims to benefit from the creative advantage of collaboration in large groups. In large groups of 60-80 people, stakeholders from all levels are brought into one room, where participants converse with each other, sharing their personal stories of the past, as well as their future desires for the issues at 
hand. Typically lasting for 16 hours spread across three days, the meeting design serves as a catalyst for mutual learning, understanding, and ultimately idea sharing (ibid).

A third collaboration technique utilized in the planning world is "planning for real", an attempt to engage local residents by creating a sense of ownership over a specific project or development. The process begins with the construction of a hand-made three-dimensional model of a neighbourhood by its residents. Participants then write place-specific suggestions on cards, and affix them directly to the corresponding area on the model..These suggestions are then prioritized by level of urgency (now, soon, and later), and use to compile a local action plan for the community (Planning for Real, 2010).

While there are a multitude of other collaborative techniques, including the more commonplace "mind-map", and charrette methods, their increasing presence within the planning profession illustrates the evolution of planning towards the paradigm of inclusion and participation, as well as the importance of maximizing creative capacity in the shaping of our environment.

Although the above techniques and theories are useful in maximizing creative solutions, if no planner, or planning department is willing or able to administer these approaches and techniques, creativity will not be maximized. In order for this to happen, employers and organizations must foster a culture of creativity from within. For Higgins and Morgan (2000), creativity in planning can be fostered through an empowering management culture that is open to suggestions, alternatives and risk-taking, utilizes staff development activities, and gives praise and credit where it is due. Consequently, this creative culture requires an equally creative leader/management team for guidance. Charismatic leaders can enable inter-organizational communication and motivation through persuasiveness, tenacity and charm (Landry, 2000). 
In summary, this section has provided an extensive background on theories of creativity, why it is important in planning, the key barriers to creativity in planning, and the necessary conditions and techniques required to maximize creativity in practice. To reiterate, the basis of this paper is: Given the assertion that planners exist within a restrictive framework that inhibits their ability to maximize creative solutions, how do currently practicing planners deal with these restrictions? Do the above assertions hold true, and if so, how are planners maximizing their creative potential? Are they?

In order to answer the questions stated above, I have set out to interview currently practicing planners at the municipal level within the Greater Toronto Area (GTA), to get their perspectives and experiences on creativity in practice. Before I continue with the methods and findings portions of this paper, it is important to clarify what this paper sets out to do (expectations), and what it doesn't: All findings, conclusions and analyses are based solely upon personal opinions, rooted in the experiences of professional planners; while these opinions and experiences cannot serve as an archetype for the entire planning profession as they are based on contextual differences and individual interpretations; they do serve as a general model for planning practice within the region. This paper does not aim to provide solutions to creative deficiencies in planning, but rather, to give voice to planners about how they view their own profession - it is an exercise in self-reflection. If nothing more, this paper strives to get students, and practitioners thinking about creativity in the planning profession - how it can be improved, and why it is important. After all, everything begins with an idea. 


\section{Chapter 3: Methodology}

\subsection{Scoping:}

The nature of the research question is inherently broad. In order to ground it, I have chosen to interview municipalities within the GTA (including those within the regions of Halton, Peel, York, Durham, and the City of Toronto. See Fig. 1).

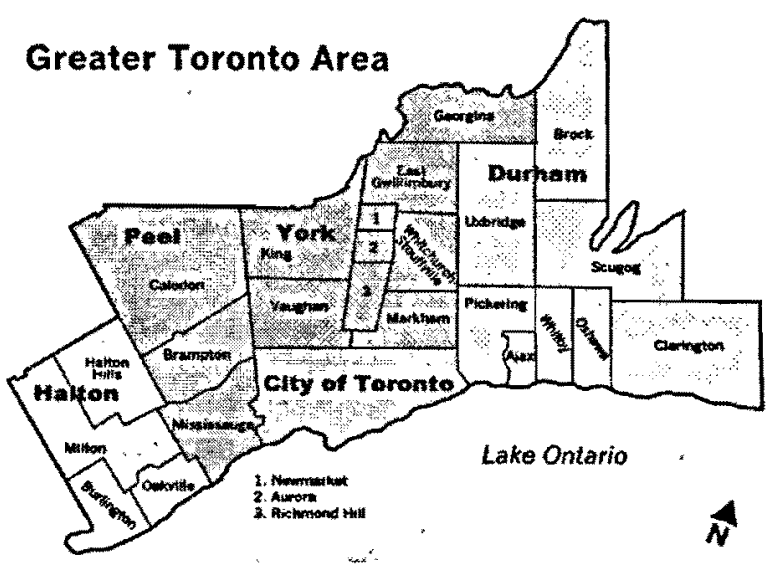

Figure 1:

Municipalities Within the Greater

Toronto Area

Although planners practice in both the private and public sectors, I have chosen to focus only on those within the public sector - the majority of background research done for this study points to restrictions to creativity within the public sector. These may or may not be the same within the private sector, however that is beyond the scope of this project.

\subsection{Subjects:}

In total, ten municipal planners from across the region were chosen - five from managerial positions (such as director of planning or department manager), and five from nonmanagerial positions (planner 1, 2, and senior). Subjects were chosen from the different levels to see if seniority made a difference in the capacity to maximize creativity. Given that much of the background research made reference to the importance of leadership in fostering a culture of creativity, my research was approached with the implicit assumption that there would be a difference in the capacity to maximize creativity between managerial (leadership) and non- 
managerial positions. In order to get a variety of perspectives from across the GTA, area municipalities (lower-tier) from all five regional municipalities (upper-tier) were targeted. Ultimately, subjects were successfully recruited from all regions except for Halton. The subject regional breakdown was as follows:

Durham Region-1 (Ajax);

Peel Region - 1;

York Region - 5 (East Gwillimbury, Markham, Richmond Hill, Vaughan); City of Toronto -3 .

\subsection{Recruitment Strategies:}

While efforts were made to recruit subjects from all municipalities, not all were able to participate. Subjects were identified based on colleague recommendations and personal networks, and initially contacted via phone and e-mail. Due to the personal nature of the study, subject anonymity was guaranteed.

\subsection{Interview Questions:}

Each subject, except for one, was interviewed in-person, with an average duration of forty-five minutes. Subjects were asked a total of thirteen questions - five specific background questions relating to their personal experience and daily work activities, and eight open-ended, theoretically based questions relating to creativity in planning. These questions were used only as a guide to direct conversation, given their open-ended nature. The nature of the questions revolved around the subjects' understanding of creativity within planning; the level of congruency between ideals learned in planning school and their application to practice; key barriers to their ability to be creative within their position; what they do to maximize creativity 
within their position; and their general thoughts on the ability of the planning profession as a whole to maximize creativity. (For the full list of questions, see appendix A).

\subsection{Data Collection and Analysis:}

All interviews were recorded using a digital voice recorder, and manually transcribed into a word document. In order to distil the vast amount of opinions and ideas, responses were separated into "managerial" and "non-managerial" groups, and further divided into four themes, based on the nature of the responses. These themes, which will form the structure for the findings section of this paper, are: the creative face of planning; the barriers to creativity in planning; the shortcomings of planning education; and the requirements for maximizing creativity. 


\section{Chapter 4: Findings}

\subsection{The Creative Face of Planning}

The complex and broad nature of the concept of 'creativity' was quite evident during the interview process, with several different understandings becoming apparent. This section will reveal the subjects' understanding of creativity within the context of planning, and the opportunities that they identified that allow for creativity within the profession.

\subsubsection{Definitions}

For a majority of the planners interviewed, creativity was about maximizing efficiency in the planning process; the ability to manoeuvre through the existing framework in order to achieve a desired goal. As one subject stated: "Creativity to me relates to the process, not the end result. So if I need to do something, I need to find every possible option or avenue to get that achieved (and) creativity helps me get to that end".

The subject goes on to further explain that creativity is an inherent part of the planning process, from the way that one goes about implementing new ideas, to policy evaluation and review:

Planning is guided by certain rules and regulations as any profession should be. On the land use side we have by-laws, we have zoning, we have (official plans). Those are the guiding principles. We have to adhere to those. But those are when the principles are set and approved. In order to get there, in order to develop those by-laws and those approval processes, you have to be creative. If you aren't, then you're not doing your job. So in other words think of it this way: If you're creating an official plan for a new town, you have to be creative, in order to create that (official plan). If you rely on other examples of other (official plans) for that community - and I'm being simple in this example - I think you're limiting yourself, because each community is unique. So you 
have to start off with that creativity. Once you've created something in the end, whether it be an (official plan), zoning by-law, what have you, then that's what you have to work with. Your creativity then becomes part of the evaluation and review of that tool, to make sure that it's doing what it's supposed to do, and it will do what it's supposed to do given changes in that community".

Similarly, another subject understood creativity in planning as a means for "process reengineering" in order to reach desired goals or objectives:

I wish I was more creative. I guess you could say I was somewhat creative. I mean I have found creative ways to do (things) ...I did find, (that) it was kind of a process reengineering. And there were creative ways I manipulated the legislation and the processes to help the town have more control over development and put systems in place. So it's a different kind of creativity but I guess it's still creative... I think my strength, as far as creativity goes is looking at the legislation, looking at our processes and seeing how we can manipulate them in different ways maybe people didn't think of to meet our municipal objectives.

The same subject goes on to explain: "Well in the context of my planning world, creativity right now, and probably for the last 10-15 years of my career, means finding new ways to do what we do - new and better ways to do what we do, in that sort of very constrained environment of the planning act and the politics that we work in".

A third subject also understood creativity as a tool for maximizing efficiency throughout the planning process:

creativity can be simply looking at your process in a way that perhaps you're getting the most out of it. I mean, you have processes that can be dealt with in a very stringent and 
bureaucratic way, or we can sort of look at the end result and say "ok how do we best get there", and "how do we leverage our process in order to get us there"... So, (creativity could be) simply as a way to expedite the process, and leveraging your time a little more effectively.

While the above definitions recognize creativity as an important part of manoeuvering through the planning process, for several subjects, creativity in planning is about constantly searching for alternative methods, and addressing current trends. As one explains: "So creativity I suppose becomes... you have to maneuver your way through the system perhaps in a creative way in order to see your agenda through. That might be another aspect of creativity - how do you manipulate the agenda in order to make things happen". As another subject explains:

From my point of view, creativity in the context of planning is really, thinking about lots of different alternatives or ways of doing things, and not getting so stuck on traditional ways and methods of doing things. Whether you're processing a subdivision application, or creating new policies.. it's looking at things from various different angles. That's one thing. The other thing is to go into areas that are uncharted for planners...I gave you an example of climate change...I'm shocked that very few municipalities and very few planning departments are working or doing anything at all on climate change... the other part is just pushing the envelope - going where other planners are not going and that's trying to understand, what are the emerging issues that are happening out there in the planning world that are going to shape us, maybe not today, but in the future. Another subject explains, creative change in planning is an incremental process, which progresses in steps; building on past foundations:

...(Creativity is the ability) to do something in a new or slightly different way than its 
been done in the past. That's what we always try to do in our long-range projects at least: A lot of the times in planning it's hard to go completely in a different direction, so instead in order to be creative ... you almost have to build on what's already been done... planning in this country is an evolution. So for us, because we're in a democracy, we can't do things the way that, say, China is doing or the way that places in the Middle East are doings things. We have a democratic process here. We have to go through that process, and we have to get everyone's buy-in. A lot of the time that takes a lot of time to do that, but frankly I mean I'd rather live here than in some of those places so I'm thankful for our process at the same time, even though it's lengthy.

The above opinions illustrate that creativity has different meanings to different people in the context of planning; it can vary from the ability to produce new ideas or progress in an entirely new direction, to the ability to maximize efficiency with the planning process, in an incremental manner.

\subsubsection{Opportunities for Creativity}

In order to assess the ability of planners to be creative, subjects were asked how they expressed their creative ideas in practice (what opportunities did they have to express creative ideas), and how they saw those ideas make their way into practice. For several, the creation or revision of Official Plan policies provided the greatest avenue for expressing creativity, however on a 5-year cyclical basis. As one subject stated, when talking about some of the innovative official policies she had come up with: "Now some of these policies may get appealed, and we'll probably have a great OMB hearing, but I think, for planners in the municipal environment, that's where creativity and getting new ideas starts, is in the OP, but you only up your OP like once every 5 
years or so": For another subject, the official plan review process allows a unique opportunity for the creation of new, innovative policies:

I think my job does (provide opportunities for creativity). I think, because I work in policy. I think if I worked on development control I'd have less opportunities. I guess they would be more micro opportunities. You'd have a development application and you're looking at the parking and (say) "ok, let's use stackers here, or go under ground, or put it up the side of the building". But I guess, in the policy world yeah... I think I do have an opportunity. If you asked me a year earlier, I think it would have been a little less, in terms of opportunities because we wouldn't be doing this 5-year (official plan) review. I'd be more focused on doing appeals...

For others, the Official Plan creation process, apart from policy creation, provided great opportunities for creativity. As one subject stated, consultation methods and community outreach were an opportunity for creativity:

Well I think just the way that we went about doing our consultation for our OP was pretty creative. We brought the public into it. We did a lot of visuals - that was one of the things that I was stressing we needed to do. Because when you're moving into a more urbanizing environment, you almost have to help people understand what it's going to look and feel like so that they can get comfortable with that, because you know for the longest time it's been strip plazas and stuff. And, just with the way that intensification has happened in some other places, it's like sometimes people just get their back up about that. So I think, yea the visualization that we did through the OP was one of the things. We even did a video for how it could transform, and then we brought in speakers... We actually developed, we called it, our OP framework. It was a diagram 
- that we did to help us to understand how we were going to get through the process of developing our new OP. Because no one had ever done that before here. We had the same plan since the 80 s basically right so.. it was a new thing for our entire department to go through. And since no one had done that before we had to be creative in terms of how we were developing our methodology, how we were laying that out for ourselves. But whereas the planning act I think only requires probably about two public meetings, we did like close to 30 . So yea we went out quite a bit. And what we're hearing now based on that, is that there (are) development applications that have come in for high density developments along Yonge and in other places (and) the public is actually using our adopted plan to make their arguments at council because they feel it's that strong of a vision from their perspective.

Aside from the official plan creation process, another subject felt the vague nature of certain planning legislation allowed for opportunities to be creative, in terms of how policy is interpreted:

Well ok let's say it has to do with the implementation of the places to grow act. We've been given a mandate to achieve a certain intensification target in our OP. And the town completed an OP review in order to achieve the 50 persons and jobs per hectare, and that kind of thing. But how we do it is completely up to us. So really we sort of took the initiative to say "ok well, let's establish a vision for the very places that have kind of been lacking that, and see how that kind of relates to our population and employment numbers and how...we (can) merge that into a way that becomes a compelling vision statement for the town. 
In addition to policy and legislative opportunities, internal communication, including meetings, and discussions were cited as providing an important forum to showcase creative ideas. As one municipal director stated:

I've said to them (staff members) ...ok I'm the new kid on the block, council's hired me for a reason so, give me your ideas and we'll get them forwarded too-we'll get them thinking in new and different ways. So we have a discussion at my staff meetings for sure about, you know, "what changes do you want to see, what things frustrate you, what ideas do you have for changing things, changing (the municipality)"?

Another director shared similar insights about leading internal meetings and discussions on new issues/material on a regular basis:

So you know (the staff members), they're not prepared, they're not even working on this stuff but hopefully it'll tweak a few ideas as they're listening to this presentation, and they'll take it back to their desk and something new will come out of it. So that's how we foster creativity within the organization...obviously the work has to get done... but when we get that chance to sit down together and talk, it's less about work and more about, well...creativity, thinking outside the box, and looking at different ideas. Based on the above opinions, there do exist several opportunities to be creative within the planning profession. Although the majority of opportunities seemed to arise during the cyclical five-year OP review process, as well as the creation of new official plans, more regular opportunities emerged through internal meetings and presentations; an attempt to foster creativity and new ideas from within.

\subsection{The Barriers to Creativity in Planning}


While the above section revealed some of the opportunities for creativity that planners have, this section illustrates some of the major barriers. These barriers can be further organized into four main categories: provincial legislation, corporate standards/regulations, governance structure/corporate culture/leadership, and resource limitations.

\subsubsection{Provincial Legislation}

The first piece of provincial legislation seen as a barrier to creativity is the Growth Plan for the Greater Golden Horseshoe. As one subject at the Director level explains:

Well I think the biggest restriction we have right now, and it's one we all welcomed, is the Growth Plan for the Greater Golden Horseshoe... (It's objectives are) lofty and they're good, but it's boiled down to that it's planning by numbers. And that has been a huge frustration...I can't tell you how hampering it is. I mean it's achieved some of its goals by you know, limiting sprawl but, it turned into this numbers exercise and from the provincial level it shouldn't be that restrictive you know. Set the policies, set the direction, and let us (the municipal level) implement it. So that, I think right now, as municipal planners, that's the (biggest restriction)... if you don't meet the numbers, if you exceed the numbers, you know.. it's insane...

In addition to the Growth Plan for the Greater Golden Horseshoe, the ability of the Ontario Municipal Board (OMB) to overturn municipal decisions was cited by two different subjects. For one subject, the OMB functions at too large of a scale to be able to make decisions at the local level:

I feel there is one that thing that is hindering creativity in this province right now, and that is the OMB. We did a lot of work as part of our OP to understand what type of community (we) wanted to be, from the ground up, not from the top down. 
And one of the things that we're very concerned about - and I know a lot of other municipalities are concerned about too - is how much (of) that input (is) going to be taken by the board when it comes to the decision. The thing that seems to happen when something is appealed to the board (is), a lot of the times it comes down to a context specific argument, vs. a town-wide, community-based argument. At the level of an $\mathrm{OP}$ we're trying to argue from the town scale, why something is appropriate in a certain place, based on the type of place we want to create. But we know, when and if we get appealed, it's going to come down to the same arguments that we've heard in the past - the context specific: "Oh, well it's buffered by this, there's green space beside it, it's not a problem to put the height and the density here"...It is a problem if it's in the wrong location. We're going to try to make the town-wide argument. Honestly we don't know where it's going to go, but that ... is one of the biggest constraints to planning in this province right now because, you have someone coming in, who has no real stake in that community, but is making the ultimate decision for how that community grows. I don't know, I think a community should have a voice, in terms of where and how they grow. It should be their decision. It shouldn't be someone coming in who really doesn't know that much about it you know. But again, it's not for me to say. Unfortunately a lot of the time when it gets to the board it comes down to legal arguments. It's not about planning anymore, it's about "what does it say, where's the comma, where's the semi colon, this is what I can argue that you were meaning to say"... I think it's really unfortunate.

Another subject explains that the level of power that the OMB holds can serve as a deterrent for planners to take risks: 
....in Ontario you have the added, and in my opinion problem, of the OMB - and I don't think that's a unique opinion - that can over turn a decision made through evidence and brought to council. So even when you are able to use the system to direct growth in a particular manner, it can be appealed by a land owner or developer to the OMB. So there's lots of hurdles to working creatively within the planning environment, and it becomes very easy to just... process the application, in a way that is the safest thing to do...

The above opinions illustrate the importance of local context and municipal decision-making in urban issues; both the Growth Plan for the Greater Golden Horseshoe, and the OMB perpetuate a high-level, top-down approach to planning that can easily lose sight of the local.

\subsubsection{Corporate Standards and Regulations}

In addition to provincial legislation, internal corporate standards and regulations were sited by several subjects as a severe barrier to creativity within planning. Perhaps the biggest hindrance to creativity is information and technology (I\&T) security standards. As a planner in a managerial position noted:

What you're finding is that, because we live in a technical age, there are almost too many technical I\&T standards that are driving business, or limiting business needs, when it should be the other way around. Business practices should determine I\&T support, but it doesn't happen that way. What happens is you've got this dinosaur, and this huge machinery of corporate I\&T standards...(For example), we had to jump through hoops to get onto Facebook. Some people would say, "well why is the government wanting to get on Facebook?" Well, who are your clients? (in this case) Your clients are kids at risk of 
violence, unemployed youth. How do they talk? Through social media...I grew up in the 80 s and we didn't have that, but you've got to understand to roll with the times, and that's how people communicate. They communicate on Twitter, Facebook, you know those types of things right. And so we wanted to reach out to the youth with a Facebook account. Well you can imagine how much grief we had to jump through to do that. And who was making the decision? Corporate I\&T. It does not work! It does not work! I would say out of all of these restrictions, this one has been the worst.... We have a certain internet browser that we use. We cannot use Firefox etc... and what do we have? We have collaboratives with other levels of government creating websites that are really really dynamite, and we can't use the appropriate internet reader to access that application, and ... it doesn't work properly when we show senior levels of government. You see what I mean? It does not work. And if you tell (corporate I\&T), they give you all these 9 yards about security. Wireless - there is no wireless here in this building, because of "security" issues. We have, for example, a Federal, Provincial, Local meeting of senior government officials, including deputy ministers coming in next week talking about urban issues across Canada such as urban poverty. We've got a face to face meeting that we're setting up at a venue here ... (and) we have been faced with some technical problems with internet security, with Firefox, with a whole host of other technical considerations, which prevent us from effectively presenting several presentations at this meeting, that hamper our creativity, because of the (lack of) creativity of corporate I\&T.

The same subject later noted that the extremely regulatory framework of municipal planning for security purposes has limited risk-taking, for fear of corrective action: 
I've been in the planning field for almost 30 years. What l've noticed over the years is that in the old days, there weren't as many of these restrictions; There weren't as many of these guidelines to prevent civil lawsuits, and I found that planners at that time were much more willing to talk, to give, to collaborate, and to share. I've found recently that it's become the opposite. It's become more difficult to get data, although the positive thing happening out of it is you do have some exceptions, like open data. I think people are beginning to realize certain things, but what's happened is it's become too... it's not as good as it once was... That's what I'm saying has gotten worse for creativity. We're now mired into a bureaucracy of over protectionism and fear of the ramifications of what we do. And people are so scared now. They are scared to be creative.

In another interview, a senior planner sited a similar issue:

You know we haven't caught up - we want to get into the social media ...(for social interaction), but we're not there yet. And I think what we need is younger people involved, and a way to get around certain city policies... For instance, all these computers at work, we can't use Twitter, we can't use Youtube, we can't use Facebook. So, how do you use those great tools to communicate with the public when you're not allowed to use them? So, that's right at the moment a stop sign or hurdle, or block to us being able to use those tools, because we can't access (them)... But it would be really useful. And I know why those restrictions are put in place, but at the moment, it's not there yet.

On a third occasion at a separate municipality, safety and security standards were noted as a barrier to internal consensus on creative ideas:

I still feel like...there (are) certain departments that - and a lot of the time it's 
engineering, unfortunately - (are) used to doing things a certain way, and they do things a certain way because of safety and security; because of standards that are set by provincial ministries. And they're not interested right now in accepting liability for something that hasn't been proven yet. So, ... really it's a BIG hindrance right now to moving in a different direction. And especially in terms of doing a lot of the sustainability stuff, you've got to get the engineers on board. It's hard though because at the end of the day it's their stamp that's going on those drawings right, and they have to be comfortable with accepting the liability that could happen, if it fails right.

These opinions illustrate the high level of influence that fear exerts on the planning process; in this case, fear of electronic information theft and corruption, and the legal ramifications of failed projects and ideas.

\subsubsection{Governance Structure/ Corporate Culture/ Leadership}

Throughout the interviews, a common theme that surfaced was the importance of progressive leadership, and a corporate culture of innovation, in order to foster creativity on an individual and organizational level. However, for many subjects; corporate culture and leadership proved to serve as a hindrance to creativity in some capacity. For example, one subject at the director level explained:

One of the biggest problems is, when young planners graduate and are looking for that first job they come in here (and) the organization slots them like a mouse in a little cubicle, and gives them a whole bunch of "work" to do - paper pushing - and slowly over time the creativity is stifled and lost. The best thing we can do with young planners when they come in here is to give them - I mean yes there's work that needs to get done - but give them the opportunity to continue being creative, and actually redefine 
their creativity through their work experience immediately before they get into the whole mouse trap of the organization right. So you got to get the planners in here, allow them to express their creativity, get them working on projects that are different, unique, and get their ideas on various things right. Because I do believe...that organizations by the very nature of being large bureaucracies do generally err to the side of stifling creativity, as opposed to promoting it. But, a lot of that also depends on the leadership of the organization. So you can't just blame the structure, it's also the people at the top.

As another subject explains, the planning profession exists within a bureaucratic entanglement that makes it difficult to maximize innovation:

I'd say the majority of the profession is still working more so almost as a mediator. There's, I would say, a small proportion of our profession that is actually interested in doing innovative and creative things, and pushing it forward through the bureaucracy to get it done. I unfortunately think sometimes it's easier just to get caught in the process. A lot of people that work as development planners get caught in the process. It becomes more about the process than about what is the end result of going through that process. I don't know if that's because of the way that planners were trained in the last few decades... I would hope not, but that's what I see happening.

For several subjects, the direction and functionality of city council ultimately plays the biggest role in limiting creative capacity:

I think probably from a day-to-day perspective, the municipal structure has the biggest impact, because if you get a dysfunctional council - and they exist - you cannot get anything done. At the same time, if you have a high functioning council and 
staff, and the industry are all on the same page, you can accomplish amazing things. And I look back again to the early part of my career - (to a major project in Toronto). (That project)... was a political vision that the council supported, that the staff was proposing, and yea it took a long time to get the market to go that direction, but you know, all three groups were on the same page finally, so it was happening... (in addition), Markham centre is a fantastic example where you had a developer who was way out there taking a huge risk, a council who supported the vision and staff who were putting this forward, and it happened, and it's now being built and it's absolutely amazing.

Similarly, for another subject:

We are civil servants (and) we must follow how council directs us. I think as good public servants we can see if there's a way to work around it to achieve those goals and objectives even better, but we have to work around that. Now that's a restriction only in the sense that we don't have the freedom of research that academics have. I can't just say "oh I think we should do a poverty report on New Chinese Immigrants". It's got to have a policy lever. I can't just do it. So there are those realistic things that limit our creativity, because we have certain priorities. In our work plan, we have certain priorities in the council agenda.

While council agenda and functionality can serve as a barrier to creativity, the highly political nature of planning in the public sector can sometimes serve as a deterrent to risk-taking, required for innovation and progression. As one subject at the director level states:

...you don't want to make a mistake that might come out in the political arena. So what you do is you take the safer route right. The difference between the public sector and 
the private sector is, in the private sector you can probably be a bit more creative and if your boss doesn't like what you've come up with, he'll you know slap you in the face and tell you to get a life and go back to the drawing board. But here, if what you've proposed gets on the council floor, and lets say its not kosher, then you're going to hear about it. You're going to hear about it from politicians and it's going to make the news and whatever. Right, so the politics of an organization, and that's the politics in terms of politicians, sometimes stifle creativity also, because of the way decisions are made (which may force you into) taking the path of least resistance.

Similarly, as another subjects states, the short-sited political agenda of some municipalities can often dominate decision-making, ignoring transformative and creative ideas over the longer term: ...there needs to be a culture of innovation in the organization that supports (creativity) first of all, that doesn't just tolerate it, but is supportive of innovation. Obviously, If I was in a senior management position, I wouldn't want to just bring an idea to council, because it sounds good. You bring an idea to council because you've done the research justifying the benefits. But even if the benefits are not short term, even if they're longterm benefits, that would be hopefully something you could justify in the spirit of creating a community over the longer term, over the 20 to 50 year time horizon rather than just the 4 to 5 year time horizon. So there needs to be that culture not only of supporting innovation but also thinking strategically and thinking for the long term, not the short term political consequences. And as we know in many (municipalities) the short term political consequences are what dominate the discussion.

Based on the above opinions, strong, cohesive leadership serves as the gateway to a creative planning department. These findings also illustrate the relative impotence of personnel in non- 
managerial positions, without a cohesive internal culture that is receptive to ideas; creativity is often dependent on the decision-making power of personnel in managerial positions, and is best cultivated internally, from the top-down.

\subsubsection{Resource Limitations}

The final theme that emerged as a barrier to creativity was a lack of resources (in the form of time, and manpower) to focus on bringing forth creative and innovative ideas. For example, in one subject's experience, municipalities are understaffed and overworked:

I don't see (creative ideas) coming out in team situations because...the environment is that we're understaffed and people are overworked, and they're just feeling like they can't catch up on what they're doing, so I don't think there's a lot of room for them to be creative. Or, if they've worked there for so many years they probably know that, you know management isn't going to be receptive (to creative ideas) so they might have given up.

Another subject explains that, while he does not feel restricted in his ability to offer creative ideas in his position, the time and manpower is not available to focus on, and implement these ideas; creativity and innovation is not a priority, but an afterthought that is considered once previous commitments have been dealt with:

I don't feel particularly restricted in terms of my ability to offer a creative solution or opportunity, because I don't really see a sort of structural barrier there. If anything, it may have to do with implementation, and that's sort of financially driven. Or, if it's a matter of simple work load, and you say "boy I'd like to work on this but I'm buried", that's a reality... It's more a question of capacity. Yes the ideas are there but I mean, I could be here 24 hours a day. I don't think there's a shortage of ideas, I think there's a 
shortage of man power. It's one of those things where you have to pick your highest priority and move for it. I think the other part of it is, creativity is something that needs to be fostered organizationally, and in some departments I don't think it is.

For several other subjects, limited time can inhibit the ability to focus on alternatives options, and ideas required for creative solutions. For example, planners in the development control department can feel rushed in order to process applications:

...the problem is, you get an application, the clock starts ticking, you want to avoid the hearing, it's costly, you've got all these lawyers upstairs, you've got all your time, and the hearing will consume your life. And you won't get to those other applications. So, studies get pushed to the side because "oh that hearing. Hey, the clock starts ticking. Oh

I' better deal with that, get the comments in, get my community consultation meetings in". That really drives it. And there's a lot of applications. I don't know what the stats are these days, but it's pretty heavy.

As another subject in a director position explains, limited time restricts municipalities' ability for community outreach and collaboration - an important requirement for maximizing creative solutions:

I guess the frustration I have is that there's never enough time to spend with all these folks, and to learn and understand...As planners we have to work to understand..."who are we planning for? Exisitng residents, but future residents too? Who's going to come?" So collaboration with our partners at York Region, the conservation authorities, all those agencies as well... is extremely important. I mean one of our biggest challenges here...right now is heritage preservation. There doesn't really seem to be any appetite for it, and we're involving the folks who run (a local heritage site), we've tried to involve 
the national heritage trust to try to give us some ideas on how we can raise the profile (of local heritage) and get some serious thought and...(perhaps) designations (and) legislation around heritage preservation...before all the development comes and people start whacking down buildings. So collaboration is key, but again it takes so much time to talk, to meet, to consult, to read. I mean I could spend just days and days just researching and reading.

In summary, it appears that some planners feel rushed and restrained by full agendas, and insufficient manpower to explore new ideas, or even employ collaboration techniques to investigate creative possibilities; creativity undoubtedly requires focus, effort and time to blossom.

\subsection{The Shortcomings of Planning Education}

As alluded to in the early stages of this paper, part of the reason I was drawn to researching the creative capacity of municipal planners was based on the suggestion that planning students have greater freedom to pursue creative ideas in the academic environment, than practicing planners in the professional environment. When subjects were asked how well the "creative ideals" learned in planning school now, transfer into practice, an overwhelming majority expressed the irrelevancy of planning school. For example, as one director of planning who has experience teaching stated, planning school lacks real-world experience:

I don't think planning school is that relevant. I mean you have to have it; you have to have a degree and you've got to learn the basics, but...often what the students tell me is that most of the courses they take are not very relevant to the real world.... They really hunger for practical, real-world experience, and so that's what I try to do in my courses... I'm just saying that there's still a lot of academic B.S. - that's the best way I 
can describe it. There could be much more emphasis placed on training planners, who are going to go out there, to not do more of the same (development), because that's not what we need (in terms of the suburbanization problems). You've got to break the mold.

For another, a major shortcoming of planning education is its inability to prepare students for the realities of political negotiation, and marketing, in order to "sell" creative ideas or developments. As an example, the subject uses her experience dealing with Landscape Architecture students: ...the thing that I find happens a lot in Landscape Architecture or Architecture specifically is that they don't think about how someone is going to be able to market . that building, or build that building, or even want to build that building. These are practical issues right... You know it would be nice to do a completely (ecologically sustainable) community in our province right. Carbon neutral? That would be fantastic. I would completely go for that. But to do it in the wrong location would be a huge misstep right now because...if that thing failed, (every developer would) be pointing to that thing and saying 'listen, the province tried it over here!...it didn't work, we don't want to do it either!", right. And then it becomes this political game, which we don't learn about enough in academia right now. I think the whole political situation and how to strategize around what's happening (is) a type of creativity that they need to start teaching more in school. Because you don't get exposed enough to that and honestly it's such a big part...

For another subject, the disconnect between academia and market realities/trends can serve as a shock to new planning professionals entering the field:

Well you know what, when I think about the transition from academia to the real world, 
it must be somewhat disappointing...I went back and got my degree... and I remember thinking, you know these poor kids are going to get out and have all these wonderful, great ideas, and then they're going to hit the legislative wall, the market wall and the political wall. And I think those are the three areas that can hit you in the face when you first get out. As planners we have wonderful creative ideas about what development should look like and where it should go, but very often it's out of sync with the market. So you have to kind of steer the market in a different direction - well that's like turning the Queen Mary! Does it stifle creativity? I don't think so, I think it maybe slows it. Similarly, as another director of planning generally states, work experience brings intangible qualities that are non-existent within the academic setting:

I think there's a sense of idealism obviously with students that fosters their creativity. But without a dose of reality, it goes nowhere...You get the space to be creative in school, but without the does of reality that work experience brings it means really nothing. I've actually seen quite a few (students) and I've worked quite a bit with students out there at Ryerson, U of T, York, and they're all good schools, but a lot of times the stuff we get back we can't really put into practical use, unless if I get one of my young planners to sit with those students and actually guide them through the process. Because that planner working here, (for) just a couple of years ...brings a dose of reality to the students' work.

In summary, the planning academic setting can shelter students from some (unfortunate) realities of real-world practice. Better integration of practical experience into curricula may help prepare new planners for important aspects of the profession, such as political and marketing perspectives. 


\subsection{Maximizing Creativity In Planning}

Along with uncovering some of the barriers to creativity and shortcomings of planning school, the interview subjects offered insight on how creativity can be maximized within planning. Similar to the barrier section, this section can be organized into two main types of requirements for maximizing creativity. These include: corporate leadership; and individual behaviour

\subsubsection{Leadership}

For several subjects, creativity within the planning profession must be fostered from the top-down. It requires the creation of a culture of creativity spear-headed by organizational leaders who are receptive to innovative ideas, and encourage work beyond daily routines. For example, one subject suggests that generating a positive morale amongst staff members is an effective method to encourage innovation:

So morale is very important. I'm a manager that believes certain rules can be broken, if the overall effect is a greater morale, and more of an attitude of your staff to want to work, to want to participate, to begin to think creatively. If you come down and say "well, you were 5 minutes late from lunch, don't do it next time, because these are the rules", I don't agree with those things. I don't care when people take breaks. Quite frankly I don't care if they take two-hour lunches. What's more important is if you allow - without abuse - that flexibility, people will want to work for you, and when people want to work for you, they will want to provide that creativity for you.

This flexibility and forgiveness can be seen in one subject's example of their Chief Administrator's approach to leadership, and the use of an internal blog:

...part of fostering creativity in an organization which we really have here very strongly, 
comes directly from the CAO. The CAO has a blog. He has a blog on the computer where we can go and interact with him. He's got "Ask The CAO" and all kinds of things up. One of the things he does is he's always giving this message out to staff: "there's no such thing as making a mistake" right. Because the moment I say you've made a mistake, you're never going to go down that road again. You're not going to be creative. It's not a mistake. Now if you do something that you believe is a mistake, the only thing I want to know from you is "what did you learn from that experience, and how would you do things differently next time?". His philosophy is that, people don't go out there on purpose in their organization to screw up. So if someone screws up, don't hang them, use it as a learning experience. And when you foster that type of culture through an organization, you're going to have a whole bunch of people starting to say "whoa, you know what it's ok, it's ok to make a mistake. It's ok to take a little bit of a risk, because I know I'm not going to lose my job".

As another subject explains, the ability for management and senior level staff to be willing to listen to staff at a lower level is one of the most important requirements for fostering a culture of creativity:

I think one of the things that really helps us here is, we have really good leadership at both our commissioner level and our CAO level. And, even my manager. I mean, he's always willing to listen to our ideas, and I think for someone in my type of position, that's the most you could hope for right now right. Because you're not in a decision making capacity, so your job is basically to bring the information forward to help inform their decision as to whether we go in a certain direction or not. And if you make your 
argument, if they buy it, if they're on the same page as you then, it's not a problem. she also goes on to explain the importance of generating a positive morale from the leadership level:

In my experience so far, when I have worked in places where I felt my creativity was valued, it came down to leadership. It's a lot of the time about what's happening at those levels - at the commissioner, $\mathrm{CAO}$, director level - that is making you feel, as someone who is working at that place - that your ideas are valued. And you know it's small things. It's (for example) passing them in the hall and they say "oh that was good work that you did on that, I'm really glad that you helped to bring forward that idea". You know it's very small things like that. Everyone wants the cookie every once in a while right, and it's very small things like that that make you feel like you should keep thinking about these things, that you should keep trying to make this a better place. If those things aren't happening, the morale in a place is going to go down and people are just going to start to push the paper. Or, if you get someone at the top that has the "it's their way or the highway" type personality, and people keep trying to bring forward ideas but they keep pushing them back, or hitting them down... again they're just going to say "why do I even bother, I'll just continue to push the paper".

While leadership can be a severe barrier to creativity, it is also a primary ingredient to maximizing it. Personnel in leadership positions have the ability to shape and mold their departments into one that is not afraid to take risks and is open creative possibilities; seemingly simplistic measures such as employee appreciation can be instrumental in fostering a culture of creativity. 


\subsubsection{Individual Behaviour}

While some barriers to creativity may be difficult to change, such as legislation, or the political agenda, planners can maximize their capacity to be creative by controlling how they act, within the professional environment. For example, building personal relationships and networks, collaboration, risk-taking, and managing personal expectations can be useful personal tools for maneuvering through barriers. As one subject in a managerial position explains:

...the only way that (creativity) can be done is through constant networking. There's no secret to it. Constant meetings, negotiations, give and take, don't demand. It's all about give and take and bringing people on side. So, for example, the city has long been having difficulty in getting confidential data from a number of sources. These can be social housing numbers, they could be crime stats from the police. What we've managed to do here is break down those walls, and convince those agencies that sharing data is a good thing. So, one of the creativity pieces that we've done here is to break down those silos, through a manner of trust. I have coffee breaks with the police, just, you know "let's talk". Some people may call it gravy, but it's not, because the only way that you can get things done for the population, for the clients that you serve, is to nurture those relationships and sometimes it means having a simple thing like a coffee. On the outside it may look like, "well all he's doing is having lunch". Not so, because everything happens through meetings and nurturing. Everything does.

For one subject, in an organization that does not attempt to foster a culture of progression and creativity, networking and internal collaboration is a method of building consensus, in order to further individual goals/ideals:

...this organization is not about (innovation and progression)...The planning department 
is really about processing applications...so my collaboration has been more internal. I'm enlisting the support of other people in parks development or economic development where I can to help make a point, or advocate for a particular project.

In addition to networking and personal relationships, maintaining a positive mentality through capping expectations and being patient, can improve morale, and the drive to be innovative. As one subject explains:

I mean you come out of school and want to (make a difference right away). I worked (on a large project) early in my career, building the downtown. Well it took a decade before we really saw things moving in the direction that we wanted them to. A decade, 10 years! There was huge frustration early on about not having things go the way that we had envisioned them. But I do think if you lose...that creativity, those ideals, that direction, then you just become one of those paper pushers. So I think it's up to the individual as much as the profession.

Similarly, another subject urges the importance of having a realistic mind-set, in order to keep a positive morale:

The other thing is (you have to) understand that the world is not perfect, and that if you want to be creative, you may not be able to solve all of the world's problems all at once, but you can whittle away at it; So just be realistic, and you might fight a battle and lose it, but you'll win the war later realizing that you have to walk before you run. So, what I'm saying is, your expectations should be capped, and be patient.

Perhaps the most effective way to maximize creativity through individual behaviour is by taking more risks. However, for several subjects, this does not happen as much as it should. For example: 
Well I think (planners) have to take more risks. You know what gets me is that everybody reads...everybody knows about peak oil, everybody knows about the issues with the environment - well almost everybody. Yet by and large - and I'm thinking more outside of the city - the same pattern of development keeps happening. Endless subdivisions, big-box retail, car dependent, all that stuff. And, some planners are trying to turn that big thing around, and others are just going with the flow. And that's the main crisis. I think that people in that kind of leadership position should know better. They should have the guts to take a stand, and tell their respective city counselors "no, we've got to do it a different way". And I'm worried...you know it's just starting to bite now with the oil crisis and all that...I mean, we haven't seen anything yet. The price of gas is going to go way up in the future, which will change all of sudden radically. We've built this massive region based on the car and it won't work anymore. So I think planners have to tell the truth, be strong, take leadership roles, take risks, and they have to anticipate beyond where society is now. They have to shape (society), influence and educate.

In summary, often times modifying individual behaviour can be a simpler, more immediate method to maximize creativity, than perhaps the large-scale amendment of legislation or internal regulations. In this respect, planners can be masters of manipulation, in order to maneuver through the web of restraints that serve as barriers to creativity. 


\section{Chapter 5: Discussion and Conclusions}

The above interview findings have presented a vast array of opinions and perspectives on creativity in the planning profession, based on the responses of ten currently practicing planners from within the GTA. Generally speaking, the findings seem to depict the relationship between creativity and planning as an inherent struggle, dictated by restrictions both systemic and contextual in nature: On one hand, fundamental provincial planning legislation and regulatory bodies (including the Growth Plan for the Greater Golden Horseshoe, and the OMB) present restrictions at a broad, abstract level, while independent corporate standards and departmental leadership impact creative capacity from a local context.

But what exactly is creativity within the context of planning? Perhaps the most intriguing finding of this study is that creativity has different "meanings" to different people, depending on local context and circumstance. Take for instance, the example that one subject gave, of his burgeoning relationships with other municipal departments, based on "coffee breaks", in order to maximize information and data sharing between them. In this case, although networking may not seem like a creative venture compared to grand visions such as the aforementioned North Oakville Secondary Plan Implementation Strategy, I would argue that, in it's given context it is creativity; In a planning department where close professional relationships that enable collaboration are seldom forged, one individual's "unique" efforts to go beyond his job description to nurture reciprocal relationships is "pushing the envelope".

This brings me to my overall analysis of the findings presented in this study. The above opinions largely paint a bleak view of the planning profession, through its struggles with the intricate web-work of bureaucratic and legislative of frameworks. But is this not a reality of life, which can hold true for other disciplines and positions; that progression is inhibited by 
restrictions in some form or another? Is not true that despite these inherent restrictions, many disciplines, including planning, have seen great triumphs and accomplishments? - for example, one need look no further than the establishment of the Ontario Greenbelt in 1995; an initiative to preserve the Greater Golden Horseshoe's natural heritage and resources from uncontrollable urban sprawl. Instances like these illustrate that barriers, such as the ones presented in this paper, can be overcome through initiative, risk-taking, collaboration, education, and leadership. In the context of planning, these qualities and strategies are best cultivated at the local municipality level, from within hierarchies of corporate leadership, and departmental management. Through the cultivation of cultures of progression, the once-gated barriers to the avenues of creativity and innovation can be swung open, and traversed. 


\section{Appendix A: Interview Questions}

\section{Interview Questions:}

1. What is your position with the municipality? (entry level planner, senior planner etc.)

2. How long have you been practicing planning?

3. What do you do in your current position? What do your daily work activities look like?

4. What does creativity mean to you, and how do you understand creativity within the context of planning? What role does it have in planning?

\section{Are you creative?}

6. Arguably, planning students tend to have more freedom for creative, "out of the box" thinking. The academic setting pushes students to be innovative and creative; creativity breeds progression, solutions and improvements to an otherwise static world. As a practitioner in the real world setting, do you feel your job enables you to bring forth creative and innovative ideas? How well do you feel the ideals learned in planning school transfer into practice?

7. How do you see your creative ideas make their way into practice, program or policies adopted by the municipality? Give some examples.

8. What are the avenues through which you express your ideas? (Group discussions, staff meetings, the director/senior calls you in and asks for your ideas, for example)

9. Do you get credit (appreciation by your colleagues etc.) for bringing forth your creative ideas?

10. How do you maximize creative solutions within your practice? Do you use techniques (charrettes, focus groups, meetings etc.)?

11. Do you feel restricted in your ability to offer creative ideas/solutions to certain issues? What are these restrictions/ barriers?

12. What can municipal planners, or the governance system do to maximize progression and innovation? Are they doing this? 


\section{References}

Albrechts, Louis. (1999). Planners as catalysts and initiators of change: the new structure plan for Flanders. European Planning Studies. 7 (5): 587-603

Albrechts, Louis. (2005). Creativity in and for Planning. Planning Theory. 4 (3)

De Bono, Edward. (1968). New think: The use of lateral thinking in the generation of new ideas. New York: Basic Books

Fazzano, Alicia \& Weiss, Marc. (2004). Curitiba, Brazil: Metropolitan economic strategy report. Global Urban Development. Retrieved on April 8, 2011 from: http:/www.globalurban.org/GUD\%20Curitiba\%20MES\%20Report.pdf

Forester, John. (1989). Planning in the face of power. Los Angeles: University of California Press

Future Search Network. (2003). What is future search? Retrieved on April 9, 2011 from: http://www.futuresearch.net/method/whatis/index.cfm

Goodman, Joseph; Laube Melissa \& Schwenk, Judith. (2007). Curitiba's Bus System is Model for Rapid Transit. Moving the Movement for Transportation Justice. Retrieved on April 8,2011 on http://www.urbanhabitat.org/node/344

Healey, Patsy. (2004). Creativity and urban governance. Policy Studies. 25 (2)

Higgins, Marilyn \& James, Morgan. (2000). The role of creativity in planning: the "creative practicioner'. Planning Education \& Research. 15 (1/2): 117-127

Hitchcock, Darcy. (2004). Curitiba, constraints and creativity: lessons from the developing world. Facilitating Responsible Solutions. 14 (3). Retrieved April 8, 2011 from: http://www.axisperformance.com/S19Curitiba.html (Hitchcock, 2004).

Innes, Judith. (1995). Planning theory's emerging paradigm: communicative action and interactive practice. Journal of Planning Education and Research. 14 (4): 233-244

Jary, David \& Jary; Julia (eds.). (2000). Collins Dictionary: Sociology (Third Edition). Glasgow: Harper/Collins

Kaufman, James C. (2009). Creativity 101. New York: Springer Publishing

Kunzmann, Klaus. (2005). Creativity in planning: a fuzzy concept? Journal of Urban and Regional Research. 26 (1)

Landry, Charles. (2000). The creative city: A toolkit for urban innovators. London: Earthscan Publications 
Mckibben, Bill. (2005). Curitiba: A Global Model for Development. Common Dreams.

Retrieved on April 8, 2011 from: http://www.commondreams.org/views05/1108-33.htm

Pink, Daniel. (2005). A Whole New Mind: Moving from the Information Age to the Conceptual Age. Riverhead Books.

Planning for Real. (2010). What is 'planning for real'? Retrieved on April 9, 2011 from: http://www.planningforreal.org.uk/planningforreal/default.html

Town of Oakville. (2003). North Oakville: secondary plan study east of Sixteen Mile Creek proposal no. PROP-41-2002. Retrieved on April 8, 2011 from:

http://www.oakville.ca/Media_Files/DevelopmentProcess/116secondaryplanworkplan2.p df

Town of Oakville. (2008). Official plan amendment number 272: North Oakville East secondary plan. Retrieved on April 8, 2011 from:

http://www.oakville.ca/Media_Files/planning08/Final_approved_North_Oakville_East_S econdary_Plan.pdf

Woodman, Richard; Sawyer, John \& Griffin, Ricky. (1993). Toward a theory of organizational creativity. The Academy of Management Review. 18 (2): 293-321 